\title{
The EEG Manifestations of Chronic Ethanol Abuse: Relation to Cerebral Cortical Atrophy
}

\author{
S. E. Newman, MD
}

\begin{abstract}
Eleven chronic alcoholic patients without other nonneurological or traumatic disease were evaluated by a simultaneous electroencephalogram and computerized axial tomogram. The findings suggested that chronic abusers of approximately 60 years of age or less may have a normal EEG despite the presence of cerebral cortical atrophy or dementia. In alcoholics over 60 years of age, the greater the severity of cerebral cortical atrophy, the greater the slowing in background frequency of the EEG. Voltage diminution and slow-wave transients also occurred more frequently in the older patients. The incidence of EEG abnormalities was greater than the incidence of CAT scan evidence for cerebral cortical atrophy in alcoholics over 60 years of age with dementia.
\end{abstract}

Newman SE: The EEG manifestations of chronic ethanol abuse: relation to cerebral cortical atrophy. Ann Neurol 3:299-304, 1978

Abnormalities of cerebral cortex associated with ethanol abuse have seldom been reported postmortem in the absence of the Wernicke-Korsakoff syndrome or without hepatic or other metabolic disease $[17,18]$. Recently, however, Fox et al [6] reported cerebral lateral ventricular enlargement diagnosed by CAT scan in 8 of 12 chronic alcoholics with normal mental status examinations by the time of hospital discharge. Kiraly et al described cerebral atrophy by CAT scan with a preponderance of cortical atrophy in most of 27 chronic alcoholics with transient organic brain syndromes that subsequently improved with abstinence (unpublished observations). The electroencephalographic effects of acute alcoholic intoxication [3, 4, 9, 12, 14], withdrawal [5], the Wernicke-Korsakoff syndrome $[1,7,10,12]$, seizures, and other neurological disorders [1] have also been well described, whereas the variety of EEG findings noted during chronic ethanol abuse have been attributed by Greenblatt et al [10] to preexisting EEG abnormalities.

This study was undertaken to assess the correlation between the EEG and simultaneously obtained CAT scan demonstrating in vivo atrophy of the cerebral cortex or cerebral lateral ventricular enlargement in chronic ethanol abusers.

\section{Case Selection}

We reviewed the charts of all inpatients at the University of Michigan Medical Center with the diagnosis of alcoholism. The initial population of patients consisted of those who had completed simultaneous successful EEG and CAT scan examinations between July, 1975, and December, 1976. For

From the EEG Laboratory, Neuropsychiatric Institute, University of Michigan Medical Center, Ann Arbor, MI.

Accepted for publication Sept 28, 1977. purposes of this study, alcoholism was defined by historical documentation, by at least two close observers of the patient, of excess alcohol use with resultant problems in the patient's physical, psychological, social, and economic spheres of functioning. Almost all patients had hat at least one episode of delirium tremens, and most were unemployed. Chronicity of addiction was established as a minimum of at least five years of continuous ethanol abuse. Patients with a sudden change in mental status (delirium) or seizures due to presumed or confirmed toxic-metabolic disturbances, debilitating cardiorespiratory disorders, or he patorenal diseases or with a history of prior head trauma, intracranial surgery, or vascular infarction were excluded because of complicating causes for both anatomical and physiological findings. All patients received appropriate nutritional therapy during the period of hospitalization prior to the EEG and CAT scan.

\section{Methods}

The routine EEG consisted of an awake, alert recording with intermittent variable-frequency photic stimulation. Natural sleep and hyperventilation were included whenever patient cooperation permitted. Recordings were obtained using the 10-20 system of standard electrode placement. All records were reviewed independently by several experienced electroencephalographers to assess the following specific features: waking occipital dominant frequency and recurrent maximum occipital voltage; location, incidence, duration, and voltage of nonparoxysmal activity (theta, theta-delta, and delta frequency transients); and nonspecific paroxysmal features (sharp waves). The EEG was considered borderline because of the rare occurrence ( 1 to 5 ) of minor $(<20$ to 40 $\mu v)$ nonparoxysmal or nonspecific paroxysmal transients, or because of excessive 14 to 18 cycle per second (cps) activity, usually in the bilateral anterior region. Abnormal records contained a dominant background frequency of
Address reprint requests to Dr Newman, Clinical Neurosciences Branch, National Institute of Neurological and Communicative Disorders and Stroke, National Institutes of Health, Berhesda, MD 20014. 
less than 8 cps or nonphysiological nonparoxysmal slowwave activity, or both.

CAT scans were performed using an EMI $160 \times 160$ matrix system. The routine procedure consisted of obtaining eight adjacent sections of $13 \mathrm{~mm}$ thickness utilizing a 25-degree craniocaudal angle to Reid's (orbitomeatal) baseline. The most caudal section was adjacent to the floor of the middle cranial fossa and passed through the posterior fossa, and the highest section demonstrated the largest amount of superficial motor-parietal cortex near the level of the vertex. Scans of all selected patients were reviewed independently by a minimum of two radiologists with knowledge only of the patient's age. They subjectively assessed cortical sulci and lateral ventricle size, judging the presence or absence of cerebral cortical atrophy and lateral ventricular enlargement. Direct quantification of sulci and ventricles was not obtained because of limitations of EMI scan measurements due to partial-volume averaging and differences in the levels of sections between patients. Criteria based on that of Huckman et al [11] and Gawler et al [8] were used to form the subjective groups of normal, mild, moderate, and marked lateral ventricular enlargement and cerebral cortical atrophy.

\section{Results}

The EEG and CAT scan were completed within less than seven days of each other for every patient except 1 (No. 6), for whom eight months elapsed. The patients' age, sex, type and duration of symptoms, relevant laboratory studies, and drug intake at the time of EEG and CAT scan are summarized in the Table. Seven of the patients had presenting complaints relating to defects in mental status, with varying amounts of demonstrable difficulty in orientation, short-term memory, long-term recall ability, and other cerebral higher integrative functions (calculations, reasoning, and abstractions). Other neurological problems ranged from symptoms of dizziness, focal headaches, and nonspecific pains in patients with normal neurological examinations to signs of ataxia, dysarthria, incontinence, and peripheral neuropathies. In a few cases, metabolic studies were initially abnormal on admission. However, diagnostic studies including cerebrospinal fluid evaluation, serological test for syphilis, and various studies of blood and serum for hepatic, renal, cardiopulmonary, and metabolic functions, urinalyses, roentgenograms, and radionuclide scans were normal at the time of the EEG and CAT scan.

The EEG was considered normal in 4 patients (Nos. $1,2,4$, and 11), borderline in 2 (Nos. 3 and 7), and abnormal in the remaining 5 patients (see the Table). The predominant feature in 2 of the 5 abnormal recordings consisted of slow-wave transients (Patients 5 and 6). The other 3 abnormal records (Patients 8, 9, and 10) demonstrated both slow-wave transients and slowing of the dominant occipital background fre- quency with lower recurrent maximal occipital voltage (20 to $40 \mu \mathrm{v})$.

The CAT scan demonstrated normal lateral cerebral ventricles in 8 patients (Nos. 1-6,9, and 10) and in 1 patient each with mild, mild to moderate, and moderate to marked ventricular enlargement (Nos. 7 , 11 , and 8 , respectively). Only 4 patients had no changes consistent with cerebral cortical atrophy, although Patient 1 demonstrated large superior cerebellar cisterns and Patient 11 had associated mild to moderate lateral ventricular enlargement. In the remaining 7 patients, variable amounts of cerebral cortical atrophy were noted, ranging from minimal right frontal (No. 2) and mild (Nos. 7, 9, and 10) to moderate (Nos. 4 and 6) and moderate to marked (No. 8) degrees. Two patients had a relatively greater amount of cerebral cortical atrophy than comparative lateral ventricular enlargement (Nos. 4 and 6), and 1 demonstrated the converse (No. 11).

Of the patients less than 60 years old with a normal CAT scan, 2 were not demented: 1 with a normal EEG (No. 1) and 1 with excessive fast activity (No. 3). A third (No. 5) had normal EEG background findings but nonparoxysmal transients, and was demented. In addition, a fourth patient (No. 2) under 60 years old with minimal focal cerebral cortical atrophy and a normal EEG was demented. The remaining 2 patients less than 60 years old had moderate cerebral cortical atrophy: Patient 4, although demented, had a normal EEG, and Patient 6 , without dementia, demonstrated normal EEG background activity but nonparoxysmal transients (Fig 1).

Demented patients (Nos. 8, 9, and 10) over 60 years of age demonstrated EEG background slowing consistent with their degree of cerebral cortical atrophy: the more severe the slowing in the dominant occipital waking frequency, the greater the amount of cerebral cortical atrophy (Figs 2,3). A single older patient (No. 11), who had abstained from ethanol, had neither background nor nonparoxysmal transient abnormalities.

\section{Discussion}

To assess properly the possible relationship between the EEG and CAT scan findings in alcoholism, the effects of age on these studies were considered. The EEG findings of slowing of background frequency and voltage diminution are greater than expected from reports in the normal aged population $[15,16]$. While patients younger than 62 years had a faster dominant background frequency (usually over $9.0 \mathrm{cps}$ ), those older than 62 tended toward much slower frequencies ( 5.5 to $9.0 \mathrm{cps}$ ). Also, the recurrent maximum occipital voltage was lower in the older group of patients. The single exception was a patient (No. 11) with a 
EEG

\begin{tabular}{|c|c|c|c|c|c|c|}
\hline \multirow{2}{*}{$\begin{array}{l}\text { Patient } \\
\text { No, Age } \\
\text { (yr), and } \\
\text { Sex } \\
\end{array}$} & \multirow[b]{2}{*}{ Symptoms/Signs } & \multicolumn{2}{|c|}{ CAT Scan } & \multicolumn{2}{|c|}{ Background } & \multirow[b]{2}{*}{ Transients } \\
\hline & & $\begin{array}{l}\text { Enlarged } \\
\text { Lateral } \\
\text { Ventricle }\end{array}$ & $\begin{array}{l}\text { Enlarged } \\
\text { Cerebral } \\
\text { Sulci }\end{array}$ & $\begin{array}{l}\text { Frequency } \\
\text { (cps) }\end{array}$ & $\begin{array}{l}\text { Amplitude } \\
(\mu \mathrm{v})\end{array}$ & \\
\hline 1. $37, \mathrm{M}$ & $\begin{array}{l}\text { Nonprogressive dizzi- } \\
\text { ness,? duration; nor- } \\
\text { mal examination }\end{array}$ & $\begin{array}{l}\text { None; large } \\
\text { superior } \\
\text { cerebellar } \\
\text { cisterns }\end{array}$ & $\begin{array}{l}\text { None; large } \\
\text { superior } \\
\text { cerebellar } \\
\text { cisterns }\end{array}$ & 10.0 & $40-60$ & None \\
\hline 2. $37, \mathrm{~F}$ & $\begin{array}{l}\text { Recent memory defects } \\
\times 1 \mathrm{yr} \text {; peripheral } \\
\text { neuropathy }\end{array}$ & None & $\begin{array}{l}\text { Minimal right } \\
\text { frontal cor- } \\
\text { tical at- } \\
\text { rophy }\end{array}$ & 10.5 & $40-60$ & None \\
\hline 3. $44, \mathrm{M}$ & $\begin{array}{l}\text { Vertigo on rotation of } \\
\text { head; BP } 180 / 100 ; \\
\text { cervical arthritis }\end{array}$ & None & None & 9.0 & $40-60$ & None \\
\hline 4. $47, \mathrm{M}$ & $\begin{array}{l}\text { Progressive memory } \\
\text { loss, confabulation, } \\
\text { witzelsucht; nystag- } \\
\text { mus, ataxia, peripheral } \\
\text { neuropathy }\end{array}$ & None & Moderate & 9.5 & $40-60$ & None \\
\hline 5. $52, \mathrm{M}$ & $\begin{array}{l}\text { Memory loss and ataxia, } \\
\text { ? duration }\end{array}$ & None & None & 9.0 & $40-60$ & $\begin{array}{l}\text { 1-4/min; } 60-100 \mu \mathrm{v} \\
\text { right temporoparietal } \\
>\text { left; serial irregular } \\
\text { theta-delta }\end{array}$ \\
\hline 6. $59, \mathrm{M}$ & $\begin{array}{l}\text { Left temporoparietal } \\
\text { headaches } \times 4 \mathrm{mo} \text {; } \\
\text { peripheral neuropathy }\end{array}$ & None & Moderate & 11.0 & $40-60$ & $\begin{array}{l}5-9 / \mathrm{min} ; 60-100 \mu \mathrm{v} \\
\text { right temporal serial } \\
\text { rhythmic and irregular } \\
\text { theta-delta and sharp } \\
\text { theta }\end{array}$ \\
\hline 7. $62, \mathrm{M}$ & $\begin{array}{l}\text { Memory loss } \times 7 \mathrm{mo} \text {; no } \\
\text { short-term recall, dis- } \\
\text { oriented }\end{array}$ & Mild & Mild & $9.0-10.0$ & $20-40$ & $\begin{array}{l}\text { Rare left temporal } \\
\text { theta-delta }\end{array}$ \\
\hline 8. $63, \mathrm{M}$ & $\begin{array}{l}\text { Disoriented, confused, } \\
\text { combative } x>1 \text { mo }\end{array}$ & $\begin{array}{l}\text { Moderate to } \\
\text { marked }\end{array}$ & $\begin{array}{l}\text { Moderate to } \\
\text { marked }\end{array}$ & $5.5-6.5$ & $20-40$ & $\begin{array}{l}20-30 / \text { min diffuse }(\mathbf{R}> \\
\text { L) serial delta }\end{array}$ \\
\hline 9. $64, \mathrm{~F}$ & $\begin{array}{l}\text { Memory loss, dis- } \\
\text { oriented, poor remote } \\
\text { recall, reasoning, and } \\
\text { calculations; bilateral } \\
\text { snout, petit pas gait, } \\
\text { incontinent }\end{array}$ & None & Mild & $7.0-8.0$ & $20-40$ & $\begin{array}{l}1-4 / \text { min shifting theta- } \\
\text { delta }\end{array}$ \\
\hline 10. $66, \mathrm{M}$ & $\begin{array}{l}\text { Disoriented, confused, } \\
\text { absent recent memory, } \\
\text { poor remote recall, } \\
\text { reasoning, abstraction, } \\
\text { calculations; nystag- } \\
\text { mus, gait ataxia } \times 1 \text { mo }\end{array}$ & None & Mild & $6.5-7.0$ & $20-40$ & $\begin{array}{l}20-30 / 30 \text { min serial ir- } \\
\quad \text { regular delta }(L>R)\end{array}$ \\
\hline 11. $68, \mathrm{M}$ & $\begin{array}{l}\text { Progressive ataxia of gait, } \\
\text { dysarthria; } L>R \\
\text { ataxia of limbs }\end{array}$ & $\begin{array}{l}\text { Mild to } \\
\text { moderate }\end{array}$ & None & 9.0 & $40-60$ & $\begin{array}{l}\text { Marked hyperventilation } \\
\text { increase of delta }\end{array}$ \\
\hline
\end{tabular}



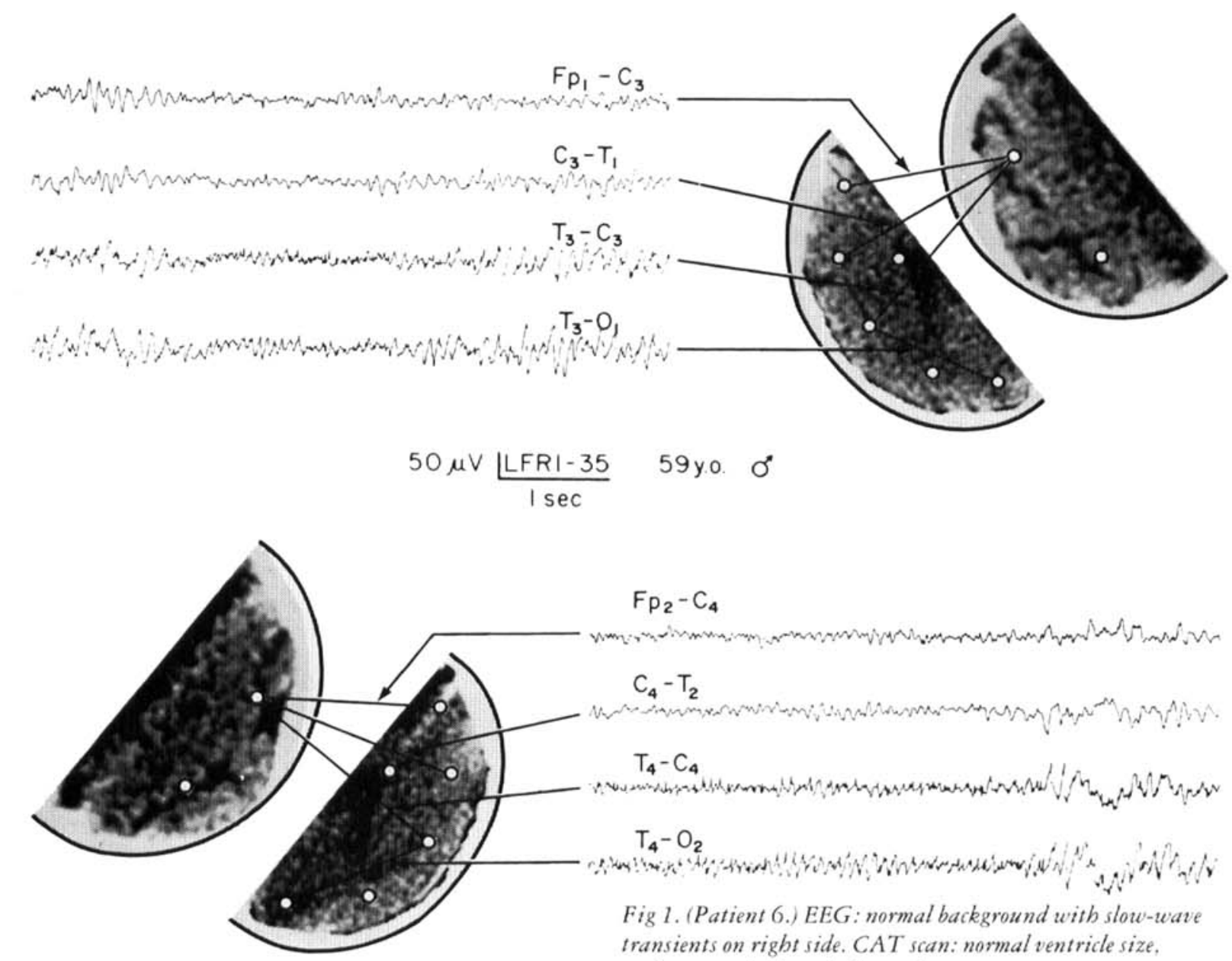

$\mathrm{Fp}_{2}-\mathrm{C}_{4}$

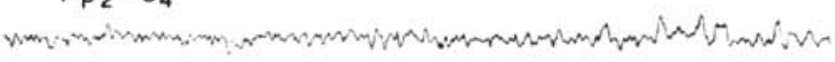
$\mathrm{C}_{4}-\mathrm{T}_{2}$ $T_{4}-C_{4}$ $\mathrm{T}_{4}-\mathrm{O}_{2}$

Fig 1. (Patient 6.) EEG: normal background with slow-wave transients on right side. CAT scan: normal ventricle size, moderate cerebral cortical at rophy.
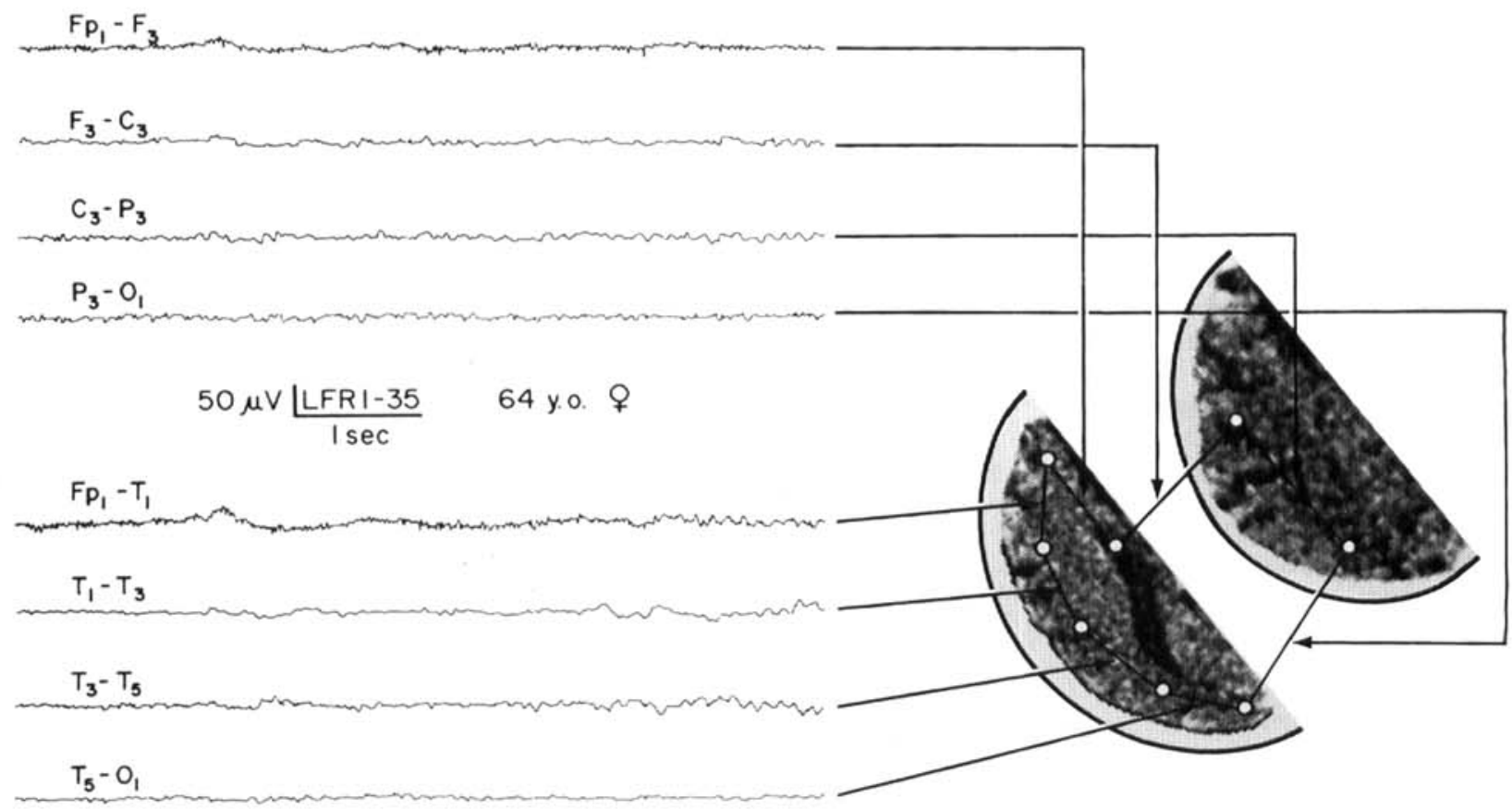

Fig 2. (Patient 9, left side.) EEG: background slowing with voltage diminished, slow-wave transients. CAT scan: normal ventricle size with mild cerebral cortical atrophy. 


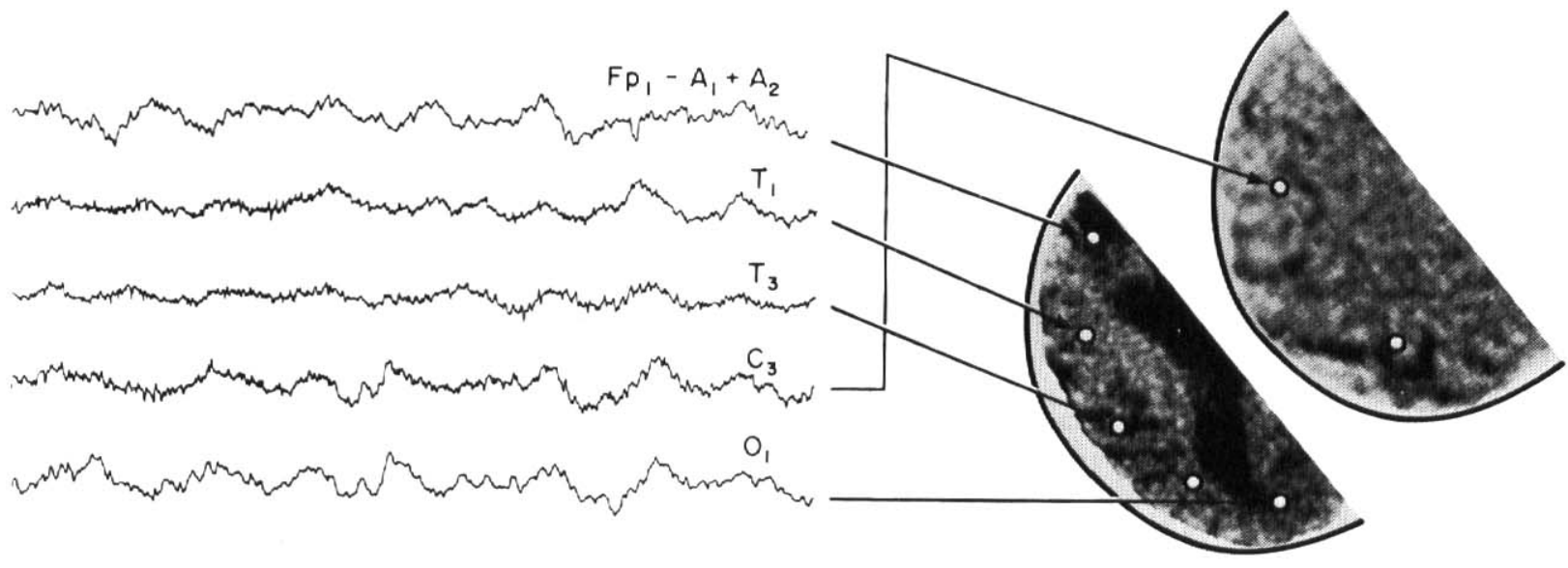

$50 \mu V \frac{\text { LLFRI-70 }}{\text { I sec }} \quad 63$ y.o. $\sigma^{\circ}$

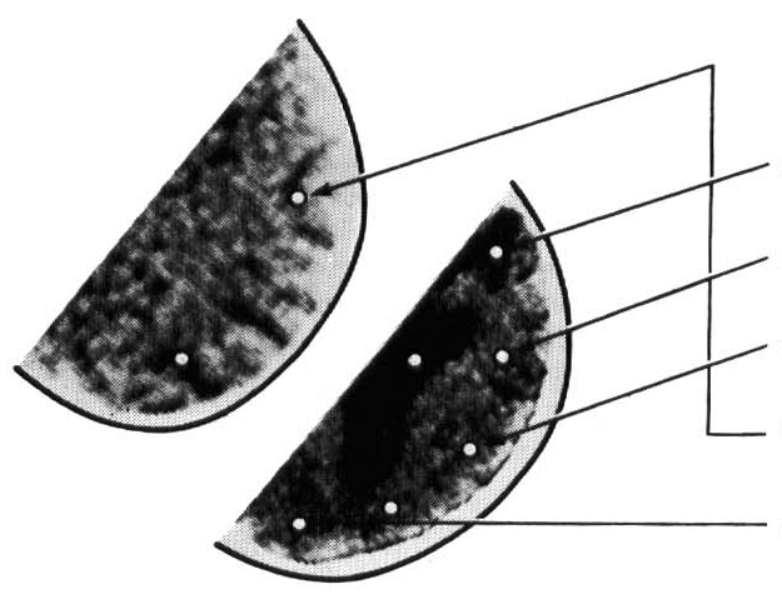

Fig 3. (Patient 8.) EEG: background slowing, diffuse slow-wave transients. CAT scan: moderate to marked ventricular enlargement with moderate to marked cerebral cortical atropby.

normal EEG background and without dementia who denied use of alcohol for at least ten years prior to examination, which might be evidence of neurophysiological recovery as a result of abstinence from ethanol.

Nonparoxysmal slow-wave transients from the left temporal region are considered a normal feature in aging [13, 15]. However, the diffuse shifting, or right-sided predominance, of serial rhythmic or irregular characteristics of nonparoxysmal transients in this study are abnormal findings regardless of age in the older patients (Nos. 8, 9,10) as well as younger patients (Nos. 5, 6).

The variable EEG features in this study are consistent with the findings noted by Victor et al [18] and may be explained by the age of the patients with Wernicke's encephalopathy or by the duration of abstinence. The 4 youngest patients (Nos. 1-4) and the

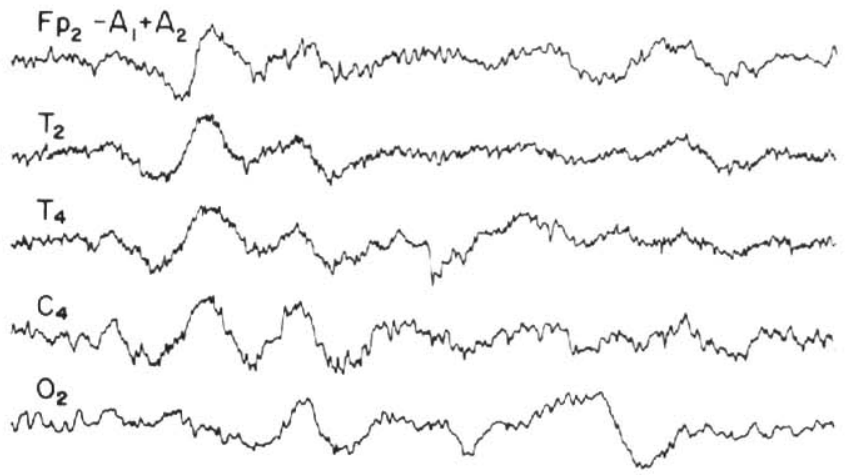

oldest patient (No. 11, an abstainer from alcohol for a prolonged time) maintained normal routine EEGs despite their individual symptomatology, physical findings, or CAT scan findings.

This limited population study tends to support the views that: (1) cerebral cortical atrophy occurs more frequently in demented chronic alcoholics than does lateral ventricular enlargement; (2) although a large disparity between the two types of atrophy may occur, they generally correlate in each patient; (3) the incidence of cerebral cortical atrophy in this study is twice as great as previously noted in patients with Wernicke-Korsakoff syndrome [18]; (4) nonphysiological temporal slow-wave transients may be premonitory electrophysiological signs of central nervous system damage; (5) background frequency slowing and voltage diminution mixed with diffuse nonparoxysmal transients may occur in older chronic alcoholics; whereas (6) discontinuation of alcohol may be related to more normal cerebral cortical physiology and gross anatomy. The presumptive histological correlation derived from postmortem examination of the brains of patients with Wernicke-Korsakoff syndrome 
suggests that the CAT scan atrophy may reflect cortical glioses and neuronal loss in the cerebrum, and that lateral ventrical enlargement may be related to atrophy of the thalamic nuclei. Longitudinal evaluation of chronic ethanol abusers is required to demonstrate progressive cerebral cortical arrophy and lateral ventricular enlargement with later EEG changes of background frequency slowing, voltage diminution, and diffuse and shifting temporal slow-wave transients.

I wish to thank Joachim F. Seeger, MD, for time and assistance in reviewing the CAT scans. I am grateful to the following members of the EEG Laboratory for assistance in reviewing the EEG records: Allan G. Clague, MD, Kenneth A. Kooi, MD, and R. P. Tucker, MD.

\section{References}

1. Arentsen K, Sundrup E: Electroencephalographic investigation of alcoholics. Acta Psychiatr Scand 39:371-383, 1963

2. Barron SA, Jacobs L, Kinkel WR: Changes in sizes of normal lateral ventricles during aging determined by computerized tomography. Neurology (Minneap) 26:1011-1013, 1976

3. Beecher HK: Chemical constitution and anesthetic potency in relation to cortical potentials. J Neurophysiol 3:347-352, 1940

4. Davis PA, Gibbs FA, Davis H, et al: The effects of alcohol on the electroencephalogram (brain waves). Q J Stud Alcohol 1:626-637, 1941

5. Engel GL, Rosenbaum M: Delirium: III. Electroencephalographic changes associated with actual alcoholic intoxication. Arch Neurol Psychiatry 53:44-50, 1945
6. Fox JM, Ramsey RG, Huckman MS, et al: Cerebral ventricular enlargement: chronic alcoholics examined by computerized tomography. JAMA 236:365-368, 1976

7. Frantzen E: Wernicke's encephalopathy. Acta Neurol Scand 42:426-441, 1966

8. Gawler J, DuBoulay GH, Bull JWD, et al: Computerized tomography (the EMI scanner): a comparison with pneumoencephalography and ventriculography. J Neurol Neurosurg Psychiatry 39:203-211, 1976

9. Gibbs FA, Uibbs EL, Lennox WG: The effects on the electroencephalogram of certain drugs which influence nervous activity. Arch Intern Med 60:154-166, 1937

10. Greenblatt $\mathbf{M}$, Levin $\mathbf{S}$, de Cori $\mathbf{F}$ : The electroencephalogram associated with chronic alcoholism, alcoholic psychosis and alcoholic convulsions. Arch Neurol Psychiatry 52:290-295, 1944

11. Huckman MS, Fox JH, Topel JL: Criteria for the diagnosis of brain atrophy by computerized tomography. Radiology 116:85-92, 1975

12. Kiloh LG, McComas AJ, Osselton JW: Clinical Electroencephalography. Third edition. London, Butrerworth \& Company, 1972, p 173

13. Kooi KA: Fundamentals of Electroencephalography. New York, Harper \& Row, 1971

14. Newman HW: The effect of alcohol on the electroencephalogram. Stanford Med Bull 17:55-60, 1959

15. Obrist WD: The electroencephalograms of normal aged adults. Electroencephalogr: Clin Neurophysiol 6:235-244, 1954

16. Silverman AJ, Busse EW, Barnes RM: Studies in the processes of aging: electroencephalographic findings in 400 elderly subjects. Electroencephalogr Clin Neurophysiol 7:67-74, 1955

17. Victor M: Alcoholism, in Baker AB, Baker LM (eds): Clinical Neurology. Hagerstown, MD, Harper \& Row, 1975

18. Victor M, Adams RD, Collins GH: The Wernicke-Korsakoff Syndrome. Philadelphia, FA Davis Company, 1971 